\title{
Obtaining of Metallized Porous Substrates for the Tubular-Type Plates of Alkaline Accumulators
}

\section{M.S. SATAEV, SH.T. KOSHKARBAEVA, G.S. KENZHIBAYEVA, A.ZH. SUIGENBAYEVA, R.R. YAKUBOVA and À.B. TLEUOVA*}

\author{
M. Auezov South Kazakhstan State University, Shymkent, Kazakhstan. \\ ${ }^{*}$ Corresponding author E-mail: tleu_aiym@mail.ru \\ http://dx.doi.org/10.13005/ojc/330333
}

(Received: April 25, 2017; Accepted: May 26, 2017)

\begin{abstract}
Possibility of obtaining of the metalized porous substrates for the tubular plates of alkaline accumulators is investigated. In this work the low-temperature gas-phase method of application of electro conductive copper phosphide films on a surface of dielectrics is used. This method allows applying a conducting layer on internal surfaces of porous materials. Besides this thin film is the catalyst of process of chemical nickel plating that gives the chance to receive the covering thickness, necessary for electrodes. The electrodes obtained in this way are used in quality tubular plates of alkaline accumulators. It is revealed, their electric characteristics are close to properties of the alkaline accumulator $\mathrm{KN}-10$. The offered way of receiving of tubular plates considerably simplifies technological process. Due to use as a basis of nonmetallic material instead of scarce metal, and also exceptions of power-intensive operations improve economic indicators of process.
\end{abstract}

Keywords: alkaline accumulators, tubular plates, copper-phosphorous films, porous materials, low temperature, gas phase, metallization

\section{INTRODUCTION}

In alkaline accumulators as a positive electrode uses a nickel-oxide electrode that takes the following basic reaction:

$\mathrm{Ni}(\mathrm{OH})_{2}+\mathrm{OH}^{-} \rightarrow \mathrm{NiOOH}+\mathrm{H}_{2} \mathrm{O}+\mathrm{e}^{-}$(charge)

$\mathrm{NiOOH}+\mathrm{H}_{2} \mathrm{O}+\mathrm{e}^{-} \rightarrow \mathrm{Ni}(\mathrm{OH})_{2}+\mathrm{OH}^{-}$(discharge)
After $70-80 \%$ charging capacity and the recharging on the nickel-oxide electrode starts to escape an oxygen:

$2 \mathrm{OH}^{-} \rightarrow 1 / 2 \mathrm{O}_{2}+\mathrm{H}_{2} \mathrm{O}+2 \mathrm{e}^{-}$(recharge)

that is reduced at the negative electrode:

$1 / 2 \mathrm{O}_{2}+\mathrm{H}_{2} \mathrm{O}+2 \mathrm{e}^{-} \rightarrow 2 \mathrm{OH}^{-}$(recharge) 
The last two reactions provide a closed oxygen cycle. Nickel-oxide electrodes in mass production produce in the following structural modifications: lamel and tubular-plate ${ }^{1}$. The lamel electrodes are connected to each other set of perforated boxes (lamellae), made from a thin $(0.1 \mathrm{~mm})$ nickel-plated steel strip. The disadvantage of these electrodes is the lowest value bit and charging current density. For removal this deficiency produces various types tubular-plate sintered (cermet) and pressed.

Sinter (cermet) consist of porous electrodes (with a porosity of at least $70 \%$ ) metal-ceramic substrate that is located in the pores of the active mass. Foundation made of carbonyl nickel fine powder which is mixed with ammonium carbonate or carbamide (60-65\% nickel, the reminder - filler) pressed onto, is rolled or sprayed on to a steel or nickel mesh. Then, the mesh of the powder is heat treated in a reducing atmosphere (usually hydrogen atmosphere) at a temperature of $800-960{ }^{\circ} \mathrm{C}$, with ammonium carbonate or carbamide decomposes and volatilizes, a nickel sinters. Thus obtained bases have a thickness of $1.0-2.3 \mathrm{~mm}$, a porosity of $80-85 \%$ and a pore radius of 5-20 microns. Basis alternately impregnated with a concentrated solution of nickel nitrate or nickel sulfate and heated to $60-90^{\circ} \mathrm{C}$ with an alkali solution that causes the precipitation of nickel oxide and hydroxides. Application of sintered electrodes eliminates swelling of the active mass, due to the unlike electrodes can bring together.

In view of the large open surface and high porosity of such electrodes can be conducted in an intensive mode of discharge; battery performance is maintained until $-50^{\circ} \mathrm{C}$; specific characteristics approximately in 1.5 times higher than that of the lamella alkaline batteries. A disadvantage of the sintered electrodes, preventing their widespread use is the high cost due to the complexity of technology and high consumption of nickel.

The varieties sintered electrodes include as well as the foil electrodes. Electrodes are produced by applying a thin $(0.05 \mathrm{~mm})$ nickel perforated tape on both sides by spraying, alcohol emulsion carbonyl nickel powder containing binders, sintering and further chemical or electrochemical impregnation of the reagents.
Electrode thickness is $0.4-0.6 \mathrm{~mm}$. The application of thin foil electrodes allows to create a compact miniature batteries. Pressed electrodes are produced by press-molding the active mass of 35-60 MPa at a steel mesh or a perforated belt. The active mass is composed of nickel hydroxide, cobalt hydroxide, graphite and a binder.

In recent years the tubular-plate felt and the foam polymer electrodes are used. Metal felt electrodes have a highly porous base made of nickel or carbon fibers. The porosity of these bases is $95 \%$ or more. Felt electrode is formed on the basis of a nickel-plated polymeric or a carbon felt. The thickness of the electrode depending on its purpose is in the range 0.8-10.0 $\mathrm{mm}$. Active mass introduced in felt by different methods depending on its density.

The felt may be used instead of foamed nickel, nickel-plated polyurethane foam obtained, followed by annealing in a reducing atmosphere. In a highly porous medium is typically made by pasting paste containing nickel hydroxide and a binder. After that a base with pasta dries and rolls. Felted and polymer foam electrodes are characterized by high specific capacity and long life ${ }^{1}$. The possibility of using copper-phosphorus films for metallization of porous materials allows to obtain on their basis various electrodes for galvanic and fuel elements and accumulators. Furthermore, such films can be incorporated into the pores of different powdered electrode, thereby, increasing of non-conductive communication with an electrically conductive active substance frame. As an analysis of literature data shows, these questions for chemical current sources are relevant.

We have developed a low-temperature process of applying copper-phosphorus films in the gas phase allows metallized porous dielectric materials. Such metallic materials may be the basis for tubular-plate alkaline accumulators. This technology is advantageous because the obtaining porous dielectric (polymer) materials are not such difficulties, as obtaining porous metallic materials. In addition, this technology allows for obtaining a plate without the application of expensive and scarce carbonyl nickel². 
In manufacturing the tubular-plates a desired porosity is about $70 \%$. The initial porosity of the metallic materials in the process of plating can be changed, whereby the plate does not get the desired capacity. Therefore, the change in porosity plating process should be negligible. Furthermore, nonmetallic materials must have sufficient mechanical strength and chemical resistance in metallization solutions. In view of these requirements, as the initial non-metallic plate was selected microporous plastic used as a separator in lead accumulators.

Microporous plastic - microporous polyvinyl chloride obtained by sintering. Microporous plastic instantaneously impregnated electrolyte has a satisfactory mechanical strength, and extremely high chemical resistance ${ }^{1}$.

\section{MATERIALS AND METHODS}

For manufacturing the electrodes the plates from microporous plastic sizes by $35^{\prime} 80 \mathrm{~mm}$ were cut, then they were degreased in a solution of following composition, g/l:

Sodium phosphate - 20 ,

$\begin{array}{ll}\text { OP- } 7 & -2.5, \\ \mathrm{~T},{ }^{\circ} \mathrm{C} & -18-25, \\ \text { Duration, min } & -5 .\end{array}$

After decreasing, it was dried at a temperature of $30-40{ }^{\circ} \mathrm{C}$ till a constant weight.

For metallized electrode plates ${ }^{3,4,6,7}$ basis initially was placed for impregnation in a solution of $\mathrm{CuSO}_{4} \times 5 \mathrm{H}_{2} \mathrm{O}(200 \mathrm{~g} / \mathrm{l})$ and stored there for the complete microporous plastic wetting for 12 hours. After impregnation the plates were discharged and dried at a temperature of $30-40^{\circ} \mathrm{C}$ for 24 hours. The dried basis was placed in a plating chamber. Carried out in gas phase chemical plating has the advantage that the metal is deposited in the pores of the plates and on the surface.

The interaction of a phosphorus-containing gas with the copper ions at room temperature, a thin, electrically conductive film is copper phosphide. Treatment is carried out till the forming a layer of copper phosphide dark steel color (20-30 minutes). Then bases were removed and rinsed thoroughly with running water and dried at room temperature.

\section{RESULTS AND DISCUSSION}

Study of metallized samples by using a scanning electron microscope ISM-6490-LV (JEOL, Japan) have shown that copper phosphide layer uniformly covers both external and internal surfaces of the porous plates.

For improving the conductivity, the basics with a conductive layer of copper phosphide treated for the alkaline electroless nickel plating. This process proceeds with low speed; therefore the depletion of the reaction mixture and nickel ions is slightly positive effect on the uniformity of the resulting nickel plating. At the electroless nickel plating, equal coatings on the surfaces of even complex configuration obtain. The presence of phosphorus in the coating imparts high hardness, wear resistance and corrosion resistance.

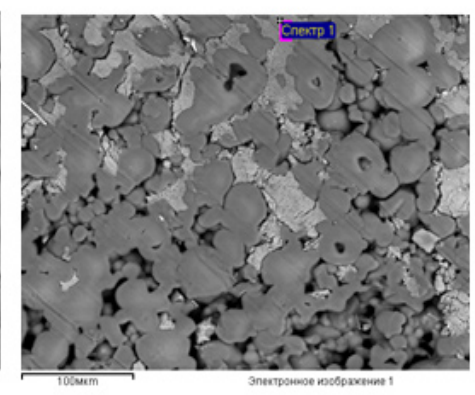

b

a

Fig. 1: Microporous plastic porous original images (a) and after the copper phosphide film coating (b) 
Table 1: Elemental analysis of initial microporous plastic and microporous plastic after copper phosphide film coating

\begin{tabular}{lc}
\hline $\begin{array}{l}\text { Initial microporous } \\
\text { plastic }\end{array}$ & $\begin{array}{c}\text { Microporous plastic } \\
\text { after copperphosphide } \\
\text { film coating }\end{array}$ \\
\hline
\end{tabular}

\begin{tabular}{cccc}
\hline Element & $\begin{array}{c}\text { Weight } \\
\%\end{array}$ & Element & $\begin{array}{c}\text { Weight } \\
\%\end{array}$ \\
\hline
\end{tabular}

\begin{tabular}{lccc} 
C & & C & \\
& & O & 50.33 \\
$\mathrm{Al}$ & 0.80 & $\mathrm{Al}$ & 2.50 \\
& & $\mathrm{P}$ & 1.62 \\
$\mathrm{~S}$ & 0.02 & $\mathrm{~S}$ & 10.79 \\
$\mathrm{Cl}$ & 29.73 & $\mathrm{Cl}$ & 5.81 \\
& & $\mathrm{Cu}$ & 19.34 \\
\hline
\end{tabular}

Chemical nickel ${ }^{5}$ is carried out in an electrolyte with the following composition, $g /$ :

$\begin{array}{lc}\text { Nickel sulfate } & -29 \\ \text { Sodium hypophosphite }-33 \\ \text { Ammonium chloride } & -44 \\ \text { Ammonia till pH } & -8.2 \\ \text { Temperature, }{ }^{\circ} \mathrm{C} & -30-40\end{array}$

The process was conducted during a half an hour. Overweight should be 0.7-0.9 g per plate. Calculations show that the amount of deposited metal is not more than $3 \%$ of the pore volume. Moreover, drying of the film of copper sulfate solution, promotes formation of a coating in a crystalline form, therefore the true surface of the solid phase with a copper-phosphorus deposition film increases. This is a favorable factor for the porous electrodes of chemical sources of electricity. After deposition of the nickel, plates were washed thoroughly in tap water and air dried at room temperature.
The obtained porous bases used for both positive and negative electrodes. For the positive plates used nickel nitrate solution and potassium hydroxide. The nickel plates were loaded into a nickel nitrate solution and soaked for two hours at a temperature of $70-80^{\circ} \mathrm{C}$. At the end of the impregnation plate discharged, and the solution was drained. Then they placed in a drying-rack-mold $\left(60{ }^{\circ} \mathrm{C}\right)$ for $100-120$ minutes. Upon completion of crystallization in the bases were charged potassium hydroxide relative density 1.19-1.21 $\mathrm{g} / \mathrm{cm}^{3}$ and kept therein for 2 hours at a temperature of $70-80^{\circ} \mathrm{C}^{1}$.

Plates, after treatment with alkali, washed by distilled water. Completion of alkali washing was determined by the absence of staining samples of wash water phenolphthalein. After washing of the alkali charged plates in an oven and dried for 2 hours at a temperature of $80-90^{\circ} \mathrm{C}$. The dried plates were weighed and subjected to a second and third treatment in the manner indicated above.

Plates after the third treatment cycle were cleaned by brush and weighed. Repeated operations will gradually form in the pores of the plates required amount of nickel hydroxide (3.85 $\mathrm{g}$ per $1 \mathrm{dm}^{2}$ of the surface). For the negative electrode, a solution of cadmium chloride with the addition of cadmium nitrate. The density of $1.60-1.63 \mathrm{~g} / \mathrm{cm}^{3}$, the resulting solution, $\mathrm{pH}=4-5$.

Prepared samples were impregnated with the solution in the composite for 2 hours at a temperature of $45-50^{\circ} \mathrm{C}$, and then dried for 2 hours in an air stream at a temperature of $80-90^{\circ} \mathrm{C}$. Upon completion of crystallization of the plates were charged into a solution of potassium hydroxide density 1.19-1.21 $\mathrm{g} / \mathrm{cm}^{3}$ and treated for 2 hours at a temperature of $50-70^{\circ} \mathrm{C}$. Then they washed in running water, flushing end checked by the absence of a weak pink color with phenolphthalein.

Table 2: The plates weight changing at the different stages of the obtaining electrodes for the tubular-plate alkaline accumulators

\begin{tabular}{lll}
\hline No. & Description & Plates weight \\
\hline 1. & Microporous plastic plates & $2.70-2.71$ \\
2. & Bases after copper sulfate solution impregnation & $2.91-2.98$ \\
3. & Bases after copper phosphorus layer application & $2.82-2.86$ \\
4. & Bases after electroless nickel plating & $3.69-3.72$ \\
5. & Bases after active mass impregnation & $5.62-5.69$ \\
\hline
\end{tabular}


Table 3 : Test results alkaline battery

\begin{tabular}{lccccc}
\hline $\begin{array}{l}\text { Number of } \\
\text { cycle }\end{array}$ & \multicolumn{2}{c}{ Charge } & \multicolumn{2}{c}{ Discharge } & $\begin{array}{c}\text { Voltage on the accumulator } \\
\text { at the discharge end net less, V }\end{array}$ \\
\cline { 2 - 4 } & current, A & time, $\mathbf{h}$ & current, A & time, $\mathbf{h}$ & \\
\hline 1. & 0.60 .3 & 5.04 .0 & 0.5 & 4.0 & 1 \\
2. & 0.60 .3 & 5.04 .0 & 0.5 & 5.0 & 1 \\
3. & 0.60 .3 & 5.04 .0 & 0.5 & 5.5 & 1 \\
4. & 0.60 .3 & 5.04 .0 & 0.5 & 6.0 & 1 \\
\hline
\end{tabular}

Plates were dried for 2 hours in an air stream at a temperature of $60-80^{\circ} \mathrm{C}$. By impregnation in a solution of alkali and salt must be at least three, gain does not yet reach 1.9-2.0 g per plate. Data on the change in mass during the production of the plates experienced electrodes alkaline battery are listed in Table 2. To provide a collector plate pierced nickel wire $(0.45 \mathrm{~mm}$ diameter).

Battery assembly was performed as follows. Two positive electrodes were placed on the wrapper of the alkali-resistant paper plates current leads passed through the hole of the wrapper. Then both electrodes wrapped into wrap in two layers, preventing violations of its territorial integrity. Later two electrodes installed in the wrapper on the work piece from a nylon fabric, so that the current leads were in the slots fit and sealed electrodes in nylon on three sides.

Straightening current positive and negative plates leads. Invested nine negative electrodes between four positive electrodes wrapped so negative in the block were extreme.

Block inserted into the device, measured thickness crimped so that the thickness of the block was 24.2-25.5 mm, inserted into a standard alkaline battery holder $\mathrm{KH}-10$ of vinyl plastic gasket in half its height. The completed electrode assembly put and inserted into the pad unit in the holder. Then block inserted into the housing unit, the beam passed through the orifice of the bridge.

The results (Table 3 ) show that the electrical characteristics of alkaline batteries with tubular plates obtained by applying copper phosphorus films on dielectric materials similar to $\mathrm{KH}-10$ accumulator data. At the same time, such plates are simplified and less expensive manufacturing process, by using as a basis a non-metallic material in place of scarce metal. This is the energy-intensive eliminates operation of sintering, burning and no need to use expensive nickel carbonyl.

\section{CONCLUSION}

Thus, the offered technology of metallization of porous dielectric materials can be used for obtaining the tubular electrodes of chemical sources of current. Use of gaseous phosphene as reducing agent, allows to reduce copper compounds on porous surfaces to phosphene which forms a basis for further metallization. In this case, the application of copper-phosphorus films on dielectric materials significantly simplify instrumentation of technological process which becomes also less energy-intensive.

\section{REFERENCES}

1. Korovin, N.V.; Skundin, A.M. Chemical current sources: - M.: Univ. MEl. 2003, 740.

2. Ilyin, V.A. Metallization of dielectrics. L.: Engineering. 2002, 80.

3. Koshkarbaeva, Sh. T.; Nauryzova, S.Z.; Sataev, M.S.; Tleuova, A.B. Orient J Chem.
2012, 28 (3), 1281-1283.

4. Satayev, M.S.; Koshkarbaeva, Sh. T.; Tukibayeva, A.; Tuleshova, E. Asian J. Chem. 2013, 25(18), 10329-10331.

5. Sataev, M.S.; Koshkarbaeva, Sh. T.; Perni, S.; Nauryzova, S.Z.; Prokopovich, P. Colloids 
Surf A Physicochem Eng Asp. 2015, 480, 384-389.

6. Shalkauskas, M.I.; Vashkyalis, A.Y. Chemical metallization of plastics. L.: Chemistry. 2000,
144.

7. Liakumovich, A.G.; Friedman, B.S.; Silberman, A.B.; Gusev, M.S. Plastics. 1989, 2, 40-43. 